\title{
DIREITO À VIDA E À PERSONALIDADE DO FETO, ABORTO E RELIGIÃO NO CONTEXTO BRASILEIRO: MULHERES ENTRE A VIDA E A MORTE
}

\author{
FETUS RIGHT TO LIFE AND PERSONALITY, ABORTION AND \\ RELIGION IN BRAZILIAN CONTEXT: WOMEN BETWEEN LIFE AND \\ DEATH
}

DANIELA ROSENDO

( Universidade Federal de Santa Catarina, Brasil)

TAMARA AMOROSO GONÇALVES

( University Concordia, Canadá)

\begin{abstract}
RESUMO
A discussão sobre aborto no Brasil é frequentemente permeada por argumentos religiosos travestidos de argumentos jurídicos. Em um Estado guiado pelo princípio da laicidade, moralidades religiosas não devem interferir em políticas públicas e nem mesmo na formulação de leis. Este artigo busca investigar o arcabouço normativo brasileiro, verificando se há subsídios suficientes, do ponto de uma ética pautada em direitos humanos, para proibir a realização do aborto eletivo com base na preservação do direito à vida e à personalidade dos fetos. Mais especificamente, analisa o direito à vida e à personalidade no direito brasileiro, percorrendo também um pouco do histórico das variações relacionadas ao posicionamento da Igreja Católica sobre o tema do aborto e seu consequente impacto no direito brasileiro. Percebe-se que têm sido utilizados argumentos religiosos para impedir o reconhecimento do direito à interrupção voluntária da gravidez, com pleno exercício da autonomia da mulher e do reconhecimento dos seus direitos como sujeito histórico e político. Essa proibição tem acarretado a morte de milhares de mulheres em todo o mundo, razão pela qual é fundamental refletir sobre os argumentos que obstam o avanço legislativo, mantidos pelo discurso masculinista antiabortista (Tiburi), que torna as mulheres referentes ausentes (Adams).
\end{abstract}

Palavras-chave: Aborto. Religião. Direito à Vida. Direitos de Personalidade.

\begin{abstract}
In Brazil, discussions on abortion laws are frequently permeated by religious arguments disguised as juridical arguments. Considering the secular principle that rules Brazilian State, religious fundaments cannot guide public policies or law making. This article investigates Brazilian law in order to better understand if there is juridical support to prohibit elective abortion based on the fetus right to life and personality. A historical background on the Catholic Church understanding regarding the subject is also considered in this article, analysing whether it does or does not impact Brazilian law. Religious arguments have been used to block the right to elective abortion, affecting women's fundamental rights and the acknowledgment of women as a historical and political actor. The illegality of abortion is responsible for the death of million women all around the world, which urges us to deepen our reflection on the arguments used to block debates in the Parliament, fomented by an antiabortion masculine discourse (Tiburi), which consider women as absent referents Adams).
\end{abstract}

Keywords: Abortion. Religion. Right to life. Personality Rights. 


\section{Introdução}

"Tanto espírito no feto e nenhum no marginal" Caetano Veloso

Muitos e intensos são os debates que envolvem a legalização do aborto, não apenas no Brasil como também no mundo. As discussões invariavelmente envolvem perspectivas religiosas travestidas de argumentações jurídicas.

Quais os limites e extensões do direito à vida e da personalidade no contexto brasileiro? Em que medida a religião interfere nesse debate afetando a salvaguarda de laicidade que rege o Estado brasileiro e mesmo o direito à pluralidade religiosa, aí incluído o direito à não professar nenhuma religião?

Quando o tema é aborto, sobram questões e faltam respostas que conciliem discurso e prática, coerência argumentativa e garantia de direitos. A ideia desse artigo é tratar de algumas dessas questões, sinalizando que a situação atual brasileira é insustentável e demanda urgentes reformas normativas, bem como a recolocação do tema no debate público de forma mais transparente e coerente.

\section{Direito à vida: perspectiva histórico-religiosa}

A sexualidade e a reprodução são aspectos centrais da vida humana. Orientam diversos aspectos da vida, inclusive as relações de parentesco, filiação etc. As regulações estatais sobre esses temas são indicativos consistentes sobre os valores culturais de determinada sociedade, dado que as relações de parentesco e reprodução constituem seus pilares estruturantes. Nesse sentido, os limites e liberdades concedidos nesse campo revelam muito sobre os padrões culturais e morais de um povo.

Historicamente, eram temas de domínio religioso, sobretudo em períodos em que religião e Estado eram oficialmente imbricados. Mediante os processos de secularização e a crescente afirmação de Estados laicos, o controle sobre os padrões reprodutivos e as associações familiares ficam a cargo das regulações civis (nos países com tradição de direito civil codificado, inspiradas no direito francês napoleônico, por meio do Código Civil). Com a influência de grupos religiosos, Estados legislam sobre os corpos e relações de afeto que 
unem as pessoas. Nesses processos, papéis sociais de gênero são conformados, de acordo com valores socioculturais e religiosos.

Nesse contexto, um importante obstáculo para o avanço de legislações relacionadas a estes temas é o fato de que normas que prescrevem papéis sociais de gênero são, na verdade, naturalizadas, como se não emanassem de uma estrutura de poder específica que as formatasse. Notadamente a partir do século XVIII, padrões relacionados a percepções sociais sobre os corpos e comportamentos de homens e mulheres foram cientificados e naturalizados de forma mais consistente, conformando crenças que repercutem até hoje sobre padrões e papeis sociais a cada um, segundo o que seria "natural" para cada sexo. Em razão disso, para o avanço em qualquer questão relacionada a estes temas é preciso em primeiro lugar reconhecer a relevância e o impacto das percepções de gênero nos diversos processos sociais, o que nem sempre acontece. Gênero ainda não é um conceito plenamente reconhecido, identificado e considerado em muitas análises, como deveria ser. "Gender, like the economy, needs to be interpreted to be understood. Policy paradigms of gender and the state resemble economic paradigms in that they provide interpretation, analysis and prescription." (HTUN, 2003, p. 29).

Por muito tempo sexualidade e reprodução estiveram instantaneamente associadas. Com o refinamento dos métodos contraceptivos, em especial com o desenvolvimento da pílula contraceptiva na década de 1960, novas perspectivas se abriram para as mulheres. Tratava-se de uma fórmula contraceptiva inteiramente sob o controle das próprias mulheres. Com isso, ampliaram-se as possibilidades de autonomia e controle sobre o próprio corpo, ao mesmo tempo que se iniciou um processo de descolamento entre sexualidade e reprodução. Embora essa separação tenha trazido maior liberdade nas relações entre homens e mulheres, foram elas que continuaram sendo majoritariamente responsáveis pela prevenção da gestação indesejada. Assim, a responsabilidade de cuidado recai, em geral, sobre a mulher, ignorandose a responsabilidade compartilhada envolvida no ato sexual e reprodutivo.

Embora até hoje associadas, essas duas esferas da vida têm se tornado cada vez mais autônomas, dadas as novas técnicas de reprodução assistida e o controle de natalidade. Mas o pleno acesso a métodos contraceptivos e a uma educação integral em sexualidade que favoreça o seu uso correto e responsável ainda não é uma realidade em todos os países. Em muitos, é possível acessar medicamentos e opções contraceptivas, mas nem sempre se tem educação em sexualidade que prepare os jovens a iniciar a vida sexual. Seja em razão da ausência de políticas públicas consistentes, seja em razão da resistência de grupos religiosos e conservadores, ou ambos. 
Se, por um lado, esses avanços tecnológicos promoveram maior liberdade sexual e reprodutiva, impulsionando inclusive o reconhecimento de campos jurídicos próprios para tratar destas questões (vide a formação dos direitos sexuais e reprodutivos no âmbito internacional), promoveu também, direta ou indiretamente, um processo de endurecimento dos entendimentos da Igreja Católica relacionados ao aborto. É a partir do final dos anos 1960 e início dos 1970 que a Igreja começa a se posicionar de forma mais radical em relação à interrupção da gestação, defendendo que "nada justifica o assassinato de um inocente", reforçando os deveres conjugais de se promover e manter a reprodução humana. Com isso, até mesmo o "aborto terapêutico" passou a ser condenado.

Importa resgatar que no âmbito do cristianismo, a defesa da vida do feto de forma absoluta é relativamente recente. Durante os seis primeiros séculos a centralidade da punição ao aborto não era relacionada à ideia de um crime contra a vida, mas a um crime contra a honra. A preocupação maior da Igreja nesse período era a manutenção do casamento monogâmico como regra para toda a sociedade, com o objetivo último de assegurar a transferência de propriedades somente a herdeiros legítimos (GONÇALVES, 2008, p. 73). Nesse período o aborto não era considerado propriamente um pecado, mas apenas uma "falta grave" que ocultaria o verdadeiro pecado, no caso, o adultério. Somente a partir do século XIX, em um contexto de secularização e de separação entre Estados nacionais e religião, é que a defesa da vida começa a surgir de forma mais consistente no discurso religioso em favor do feto como bem absoluto e a ideia de aborto como um pecado em si começa a se difundir (GONÇALVES, 2008, p. 51).

É também por volta deste período (décadas de 1970 e 1980) que diversos países promovem mudanças legislativas no sentido de permitir o aborto eletivo, embasados em diferentes fundamentos: direito à autonomia privada que permita a participação da mulher no mercado de trabalho de forma mais competitiva para os países de tradições liberais, ou direito à igualdade e direito à saúde para aqueles com tradição socialista (minimizar os riscos de saúde pública e assegurar a presença das mulheres no mercado de trabalho). Estas mudanças legislativas vieram também "em bloco", ou seja, surgiram em uma sequência de mudanças normativas que visavam assegurar maior igualdade às mulheres. Assim, alterações nas legislações civis relacionadas a casamento, divórcio, administração de bens etc. foram acompanhadas pelo fortalecimento dos direitos sexuais e reprodutivos e consequente legalização do aborto na América do Norte e Europa ocidental.

Nestes países (EUA, França, Alemanha etc.) grupos feministas em geral contaram com 
o apoio destes grupos políticos para assegurar o direito ao aborto seguro. Entretanto, isso não aconteceu na América Latina, onde políticos de ambas as orientações tendem a rejeitar ostensivamente o enfrentamento do tema, seja porque tratá-lo publicamente pode ter impactos eleitorais relevantes (medo de rejeição, considerando que a maioria dos cidadãos destes países se identifica como católicos ou evangélicos), seja por convicções pessoais (HTUN, 2003, p. 46).

Na América Latina em geral, mas em especial no Brasil, discussões sobre direitos humanos lato sensu e sobre direitos das mulheres foram fortemente marcadas pelo trauma dos regimes ditatoriais experienciados nestes países. Quando findos os períodos ditatoriais por volta dos anos 1980, as novas democracias da região das Américas encontraram um terreno bem menos permeável à legalização do aborto, seja em razão do background moral, religioso e conservador (reforçado durante os períodos militares), seja porque encontrou uma estrutura extremamente bem-organizada de grupos conservadores e religiosos para barrar qualquer avanço nesse sentido. Data desse período o endurecimento da Igreja em relação ao tema, condenando inclusive o aborto terapêutico, o que veio acompanhado do fortalecimento de organizações "pró-vida” (do feto), devidamente articuladas na região (HTUN, 2003, p. 175).

Soma-se ao contexto cultural o trauma da violência da ditadura e a necessidade de se afirmar política e publicamente a proteção da vida humana, considerando a grande quantidade de mortos e desaparecidos produzida pelo período do regime militar. Ainda que os temas comportem discussões de diversas envergaduras e debates jurídicos e morais diversos, esse contexto influenciou o silenciamento sobre a questão do aborto. Adicionalmente, na tentativa de se consolidar as estruturas democráticas, coalizões foram formadas a fim de se evitar temas demasiadamente polêmicos. Todos esses ingredientes compõem, portanto, um verdadeiro véu de obscurantismo e de desinformações sobre o tema. Não raro, discussões que buscam ampliar as possibilidades de realização de aborto legal são travadas de um certo ângulo que privilegia um posicionamento conservador e baseado na ampliação de uma moralidade individual ("sou contra o aborto") à toda a sociedade, sem que necessariamente se compreendam as consequências jurídicas, políticas e morais disso. Consequentemente, determinadas visões religiosas são indevidamente impostas à toda a população, ferindo a laicidade estatal e aprisionando a discussão em um falso e nebuloso debate.

A "questão do aborto", do ponto normativo, insere-se no campo dos direitos sexuais e reprodutivos e, em países nos quais a prática é criminalizada, torna-se também matéria de direito penal. Países que partilham de normas penais relacionadas ao aborto tendem a apresentar um cenário complexo e intrincado de violações a direitos humanos, bem como 
dificuldades enfrentadas por mulheres no exercício de seus direitos sexuais reprodutivos, seja para acesso a programas de planejamento familiar, seja na impossibilidade de acessar serviços de abortamento seguros, que colocam em risco a vida das mulheres na região, aumentando sobremaneira os índices de mortalidade materna:

\begin{abstract}
De acordo com a informação enviada, a Comissão pôde identificar que uma cifra elevada de mortalidade materna tem como causa principal o aborto, por exemplo, $29,1 \%$ na Argentina; $26 \%$ no Chile. No mesmo sentido constatou-se que outra cifra elevada se relaciona com causas vinculadas à gestação e parto: na Bolívia morrem em decorrência do parto $58 \%$ das mulheres e nas áreas rurais $63,5 \%$ e em razão da gestação $26,8 \%$ na área urbana e $20,4 \%$ na área rural; no Chile $39,7 \%$. No Perú a mortalidade materna alcança uma média de 261 mortes por 100 mil nascimentos, Perú ocupa o terceiro lugar, depois da Bolívia e Haiti. Na área rural duplica a porcentagem de mortalidade materna, em relação às áreas urbanas; na República Dominicana a taxa de mortalidade materna é de 185 por 100.000 nascidos vivos. Nos Estados Unidos, a média é de apenas 12 mortes por 100.000 nascimentos. (COMISSÃO INTERAMERICANA DE DIREITOS HUMANOS, 1998).
\end{abstract}

O Código Penal brasileiro, em seu artigo 128, prevê dois casos de não punibilidade para a prática do aborto: em caso de risco de vida para a mãe e de gravidez resultante de estupro. Quando adotado, tratava-se de verdadeira legislação de vanguarda, na medida em que contemplava o "aborto emocional", permitindo a interrupção da gestação em casos de estupro. Embora essa permissão tenha aberto algumas perspectivas para as mulheres, deve-se notar que se relaciona muito mais à defesa da "honra" do homem que se reflete na postura sexual da mulher do que de fato com a preservação da integridade da mulher, o que se coaduna com a estrutura machista-patriarcal que organiza as sociedades da América Latina.

Em 2012, com o julgamento da Arguição de Descumprimento de Preceito Fundamental $n^{0} 54$ pelo Supremo Tribunal Federal, pode-se dizer que os permissivos para a interrupção legal da gestação foram ampliados, abrangendo também os casos de fetos anencéfalos. A ADPF $n^{\circ} 54$ foi oferecida pela Confederação dos Profissionais de Saúde, buscando consolidar o permissivo legal para que a mulher pudesse interromper a gestação em caso de fetos anencéfalos, se assim o desejasse. Desde o final da década de 1980, com o desenvolvimento das tecnologias de ultrassom, tem sido possível identificar com cada vez maior clareza as condições de saúde dos fetos em gestação. A partir de então, o diagnóstico de anencefalia (má-formação do tubo encefálico que implica a inviabilidade da vida extrauterina) tem se tornado cada vez mais preciso e as mulheres passaram a buscar o direito de interromper a gestação nesses casos perante os tribunais brasileiros. As respostas das cortes brasileiras foram as mais variadas possíveis ${ }^{1}$ e em 2012 o STF consolidou o entendimento de 
que é legal a interrupção da gestação em casos de anencefalia, caso esse seja o desejo da mulher.

Importa ainda notar que mesmo nos casos em que o aborto é legal no Brasil, na prática as mulheres têm excepcional dificuldade em acessar esse serviço, nos centros urbanos ou em áreas rurais. Esta situação expõe a riscos de saúde sexual e reprodutiva - e em muitos casos a própria vida das mulheres corre perigo - principalmente as mulheres de baixa renda, estabelecendo uma desigualdade entre as próprias mulheres e indicando que a negação de um direito está atrelada a uma perspectiva tanto de reconhecimento das especificidades de determinado sujeito social - mulher - como de uma particular inserção social - mulheres de classes sociais menos favorecidas. Este contexto não ocorre com exclusividade no Brasil, mas bem ao contrário, é compartilhado com a maioria dos países da América Latina e do Caribe.

Muitos que se opõem à legalização do aborto apresentam a necessidade de fortalecer as políticas de planejamento familiar como forma de se prevenir a incidência de abortos. Fato é que nenhum método contraceptivo é $100 \%$ seguro e falhas podem ocorrer. Ao mesmo tempo, a presença de uma política pública consistente de planejamento familiar - que inclua também educação integral em sexualidade nas escolas públicas - não se confunde ou dissipa a necessidade de se discutir a possibilidade de as mulheres legalmente interromperem a gestação por vontade própria, independente de condicionantes como "risco de vida" ou "ser vítima de violência sexual".

A impossibilidade de se realizar o abortamento na rede pública de saúde, de forma legal e segura, empurra muitas mulheres para a prática clandestina desse procedimento. Com isso, um procedimento médico considerado dos mais seguros, torna-se extremamente arriscado, colocando em risco a vida da mulher e a sua saúde sexual e reprodutiva.

A "questão do aborto" não é privilégio apenas do Brasil. Outros países possuem políticas igualmente restritivas ou até mesmo mais restritivas que o Brasil. De qualquer forma, em países em que o procedimento reveste-se de ilegalidade, em geral há uma taxa de mortalidade materna correspondente altíssima:

\footnotetext{
A Organização Mundial da Saúde (OMS) define clinicamente por abortamento a interrupção da gravidez até a $22^{\mathrm{a}}$ semana, com produto da concepção pesando menos que 500 gramas. $\mathrm{O}$ aborto é considerado inseguro quando praticado em condições sanitárias precárias ou inadequadas e/ou quando realizado por pessoas não capacitadas (11). A cada ano, cerca de 20 milhões de abortos são praticados no mundo em condições de risco. Quase 95\% desses abortos são realizados em países em desenvolvimento, os mesmos que insistem em manter leis severas e ineptas que proíbem o aborto. Como resultado, até $25 \%$ da mortalidade materna resulta diretamente do aborto inseguro, levando desnecessariamente à morte quase $67 \mathrm{mil}$
} 
mulheres a cada ano (12). As evidências são contundentes em demonstrar a ineficácia da proibição do aborto como forma de evitar sua prática, contrastando com os efeitos dramáticos da proibição legal sobre a morte de mulheres (8). (DREZZETT e PEDROSO, 2012, p. 35-36)

A ilegalidade do aborto também contribui para que seja difícil precisar a dimensão do problema. Em países nos quais o aborto é tratado no âmbito da norma penal, apenas aqueles casos "que não deram certo", ou seja, que resultaram em complicações médicas e foram descobertos por alguma razão têm chances de serem punidos e, portanto, contabilizados. Como contabilizar algo que é considerado ilegal? Contamos apenas com estimativas e subnotificações que norteiam discussões a respeito, em geral sob a perspectiva da saúde pública.

Diversos tratados e documentos internacionais de direitos humanos tratam do tema, mais ou menos explicitamente, em geral relacionando-o à mortalidade materna e outras dificuldades enfrentadas no exercício de direitos sexuais e reprodutivos. Nesse sentido, a Declaração e a Plataforma de Ação de Pequim, de 1995, endossaram a concepção de interdependência de direitos mas deram destaque a questões relacionadas aos direitos das mulheres e aos seus direitos sexuais e reprodutivos. Particularmente sobre o aborto, afirmouse que: "na maior parte dos países, a violação aos direitos sexuais e reprodutivos das mulheres limita dramaticamente suas oportunidades na vida pública e privada, suas oportunidades de acesso à educação e o pleno exercício dos demais direitos".

A Convenção das Nações Unidas para a Eliminação de Todas as Formas de Discriminação contra as Mulheres não trata diretamente da questão do aborto mas na Recomendação Geral n 19 do respectivo Comitê (CEDAW, 1992) recomenda que os Estados-parte adotem medidas para prevenir que a vida das mulheres seja ameaçada por abortamentos inseguros. Contudo, essa recomendação não é cumprida pelo Estado, conforme afirmou o Consórcio Nacional de Redes e Organizações do Projeto de Monitoramento da CEDAW (2015, p. 20-23).

Para países que mantém uma legislação restritiva em relação ao aborto, é recorrente a recomendação do Comitê para que seja revogada essa previsão legal. Outros Comitês da ONU também se manifestam acerca da questão, por exemplo o Comitê de Direitos Humanos, que em sua Recomendação Geral $n^{\circ} 24$ recomenda a extinção das medidas punitivas impostas a mulheres que se submeteram a abortos (PIOVESAN, 2008, p. 239).

A América Latina é uma região fortemente marcada por uma estrutura patriarcal e que 
conta com uma intensa influência religiosa de grupos católicos no âmbito das mais altas cúpulas de poder. Nestes países a religião, em especial a católica, interfere diretamente nas políticas públicas promovidas pelo Executivo, nos debates presentes no Poder Legislativo e inclusive podem interferir em decisões do Judiciário.

Assim, boa parte dos países da região têm normas restritivas em relação ao aborto. Argentina e Brasil possuem parâmetros normativos semelhantes mas realidades diferenciadas. Há extremos também, como El Salvador que conta atualmente com denúncias de mulheres sendo presas e condenadas inclusive em casos de abortos espontâneos e o Uruguai, em que uma recente ampliação dos permissivos legais relacionados ao aborto, conseguida pelo viés da promoção da saúde pública das mulheres, tem contribuído para uma significativa redução dos índices de mortalidade materna.

A Organização dos Estados Americanos não conta com uma Convenção específica sobre direitos sexuais e reprodutivos - embora grupos e movimentos sociais venham buscando a sua discussão. Mas o Pacto Interamericano de Direitos Civis e Políticos, conhecido como Pacto de São José da Costa Rica, que trata do direito à vida, é muitas vezes invocado para se reafirmar a restrição absoluta ao acesso ao aborto e mesmo à contracepção de emergência (conhecida amplamente como "a pílula do dia seguinte”).

Nesse contexto, diversos países da região das Américas têm falhado no processo de legalização do aborto, colocando em risco a vida e a saúde sexual e reprodutiva de milhares de mulheres, em especial as de baixa renda. A seguir enfrentaremos com mais detalhes os argumentos que muitas vezes são utilizados para defender o direito à vida do feto de forma absoluta. Tratam-se, na realidade, de argumentos religiosos travestidos de juridicidade, dado que o discurso de mero controle da sexualidade das mulheres não mais se sustenta no século XXI, razão pela qual essas justificativas, embasadas por moralidades religiosas, cooptaram a argumentação de direitos humanos para embasar restrições à realização do aborto de forma legal e segura ${ }^{2}$, arbitrariamente defendendo o direito absoluto à vida do feto e deixando de lado os direitos, inclusive à vida, das mulheres.

\section{Direito à vida do feto no direito brasileiro}

Para a doutrina jurídica brasileira, o conceito de pessoa envolve "o ser, individual ou coletivo, dotado de direitos e deveres" (NADER, 2012, p. 287). Essa vinculação aos direitos e deveres ocorre a partir da concepção jurídica do termo pessoa, de modo que a própria doutrina afirma que existem outras acepções, como a biológica, a religiosa e a filosófica. 
A personalidade jurídica é considerada atributo essencial do ser humano, vinculado justamente aos direitos e deveres reconhecidos a todas as pessoas pela ordem jurídica (NADER, 2012, p. 286), conforme disposto no artigo $1^{\text {o }}$ do Código Civil (“Art. 1. Toda pessoa é capaz de direitos e deveres na ordem civil."). Tratando-se da pessoa natural, faz-se necessário determinar quando iniciam e quando cessam esses direitos e deveres, ou seja, quando ocorre o início e o fím da personalidade. Dispõe o Código Civil: "Art. 20 . A personalidade civil da pessoa começa do nascimento com vida; mas a lei põe a salvo, desde a concepção, os direitos do nascituro" (BRASIL, 2002).

Enquanto o início da personalidade é determinado pelo nascimento com vida, o seu término é marcado pela morte: “Art. $6^{\circ}$. A existência da pessoa natural termina com a morte; presume-se esta, quanto aos ausentes, nos casos em que a lei autoriza a abertura de sucessão definitiva” (BRASIL, 2002).

A esse conceito de pessoa atrela-se o conceito de sujeito de direito, que pode ser tanto a pessoa natural (ou física) quanto a jurídica. Nesse sentido:

[...] todo sujeito de direito é também uma pessoa. [...] Pessoa é, por outras palavras, a dimensão atributiva do ser humano, ou seja, a qualificação do invidíduo como ser social enquanto se afirma e se correlaciona no seio da convivência através de laços éticos-jurídicos, tendo o Código Civil de 2002 todo um Capítulo dedicado aos direitos da personalidade (arts. 11 a 21).

[...] No plano jurídico, a personalidade é isto: a capacidade genérica de ser sujeito de direitos, o que é expressão de sua autonomia moral. (REALE, 2012, p. 231232) (grifo do autor)

Embora o Código Civil disponha que os direitos da personalidade iniciam com o nascimento com vida, alguns direitos são resguardados ao nascituro, chegando-se inclusive a lhe atribuir "dignidade como pessoa humana" (DINIZ, 2006, p. 129). Nesse sentido:

\footnotetext{
O embrião, ou o nascituro, tem resguardados, normativamente, desde a concepção, os seus direitos, porque a partir dela passa a ter existência e vida orgânica e biológica própria, independente da de sua mãe. Se as normas o protegem é porque tem personalidade jurídica. Na vida intra-uterina, ou mesmo in vitro, tem personalidade jurídica formal, relativamente aos direitos da personalidade, consagrados constitucionalmente, adquirindo personalidade jurídica material apenas se nascer com vida, ocasião em que será titular dos direitos patrimoniais e dos obrigacionais, que se encontravam em estado potencial, e dos direitos às indenizações por dano moral e patrimonial por ele sofrido. (DINIZ, 2006, p. 127128) (grifo da autora)
}

A doutrina jurídica parece não ter um conceito de pessoa distinto do conceito de ser humano, sendo essa a condição para que sejam atribuídos direitos e deveres a alguém. Se 
ninguém pode ser excluído pela lei, a condição para que seja um sujeito de direito é o nascimento com vida, até que ela cesse. Nos termos do Código Civil, o feto (chamado nascituro) ainda não é ainda pessoa, mas também tem direitos resguardados, inclusive os de personalidade. Trata-se de direitos em abstrato que existem em potência e são imediatamente atribuídos mediante o nascimento com vida. Não há uma especificação clara de qual critério é utilizado pela legislação para definir o sujeito de direito, compreendido não meramente como a pessoa, mas como aquele que tem direitos e, por vezes, deveres.

Nesse sentido, o conceito de sujeito de direito não precisa estar necessariamente vinculado ao de pessoa. No Brasil, os animais não são reconhecidos como sujeitos de direitos mas na França, por exemplo, a recente aprovação do Código Civil reconhece que os animais são seres senscientes e, consequentemente, lhes são atribuídos direitos como sujeitos, mesmo não sendo pessoas humanas (AVANCINI, 2015). Esse fato demonstra, portanto, o que Norberto Bobbio afirma em relação aos direitos: eles não são absolutos, mas construídos historicamente formando uma classe variável. "Não se concebe como seja possível atribuir um fundamento absoluto a direitos historicamente relativos” (BOBBIO, 2004, p. 38).

Assim, quando Diniz afirma que "Se as normas o protegem é porque tem personalidade jurídica", a autora parece inverter a relação e utilizar a norma para fundamentar a própria existência dela. Ou seja, ao invés de a personalidade jurídica ser atribuída pela norma, Diniz tenta justificar o direito do nascituro como algo absoluto, como se a personalidade jurídica pudesse existir antes de ser definida pela norma. Se os direitos não são absolutos, a norma em si não pode justificar sua própria existência.

Diniz busca o fundamento do direito do embrião ou do nascituro na sua própria vida, alegando que ela é independente da vida de sua mãe. A autora ignora, portanto, o fato de que o feto depende da gestante para existir, em potência. Márcia Tiburi (2014, p. 166) afirma que esse tipo de argumento reflete um posicionamento masculinista antiabortista, cujo discurso revela outro tipo de aborto: não mais o do feto, mas o das "próprias mulheres, seu desejo, sua autocompreensão, sua liberdade.”

O foco na vida do embrião ignora as mulheres como sujeitos históricos e políticos. Tiburi afirma que o masculinismo antiabortista se reflete no âmbito jurídico ao estabelecer um estatuto de pertença, ou seja, de que o embrião não pertence ao corpo da mulher no qual está.

Inventa-se, a propósito, metafisicamente, a especialidade dessa pertença. $\mathrm{O}$ estatuto da pertença é considerado tão especial como a "vida" do embrião, nunca a vida de uma mulher é considerada no mesmo amplo sentido (potencialidade, direito, política) com que o embrião é revestido do conceito de vida. Argumenta-se na 
direção da potência do embrião como vida humana sem que se pense na vida da mulher. (TIBURI, 2014, p. 167)

A mulher passa a ser vista somente como mãe e um "meio do vir a ser do embrião", contrariando explicitamente o fundamento kantiano da dignidade, segundo o qual nenhuma pessoa pode ser meio, mas sempre fim. Essa assimetria jurídica é reflexo da filosofia e da teologia misóginas, explica Tiburi (2014, p. 168).

Carol J. Adams (1994, p. 69-70) explica que somente quem está vivendo pode sentimentalizar a ideia da vida sem si mesmo, ou seja, quem nunca existiu não pode saber de sua não-existência. Logo, somente quem já está vivendo sua vida individualmente pode afirmar que "não gostaria de ter sido abortado". Entretanto, esse tipo de argumento personaliza um estado que não existe, isto é, o não-ser, razão pela qual é possível afirmar que o feto não pode experenciar a privação da vida.

Percebe-se que ao dispôr sobre o feto, a doutrina jurídica oscila entre o argumento da vida e o da pessoa, embora não haja uma definição conceitual precisa de cada um deles. Nesse sentido, Ronald Dworkin afirma que existem duas formas distintas de objeção ao aborto: a derivativa e a independente. A primeira se relaciona com direitos e deveres, ao passo que a segunda diz respeito ao valor intrínseco, à santidade (interpretada de forma secular) ou inviolabilidade da vida humana.

Segundo Dworkin (2009, p. 12/23-24), para ter interesse próprio é necessário que se tenha (ou tenha tido) alguma forma de consciência. Não basta que esteja em vias de se transformar em um ser humano completo. Interesses se relacionam com capacidades complexas, tais quais sentir prazer, afeições, emoções, expectativas, decepções, os quais surgem em algum momento tardio da gestação. Portanto, um feto imaturo não pode ter interesses.

Assim, aparentemente, as opiniões divergentes em relação ao aborto ocorrem em virtude da discussão sobre o fato de o feto ser ou não uma pessoa, cujo direito à vida iniciaria na concepção, ou, sendo pessoa, se seu direito à vida prevalece em detrimento do direito da gestante (DWORKIN, 2009, p. 41-42).

Dworkin afirma que embora os debates pareçam se situar na objeção derivativa, tratase, na verdade, da objeção independente. Pessoas que defendem que fetos têm interesses e direitos não poderiam admitir que o aborto é permissível em alguns casos. Por isso, Dworkin entende que elas se baseiam na sacralidade da vida, e não nos direitos, pois, segundo o filósofo, mesmo as religiões concedem exceções em alguns casos. 


\begin{abstract}
A estrutura detalhada da maior parte da opinião conservadora sobre o aborto é na verdade incompatível com o pressuposto de que o feto tem direito já a partir de sua concepção, e a estrutura detalhada da maior parte da opinião liberal não pode ser explicada apenas com base no pressuposto de que tais direitos inexistem. (DWORKIN, 2009, p. 42).
\end{abstract}

Feitas essas ponderações, Dworkin (2009, p. 130-131) entende que o debate sobre o aborto deve estar centralizado na questão filosófica relativa à frustração de uma vida biológica a fim de justificar que se evite a frustração de uma contribuição a essa vida ou a outras vidas. Nesse abordagem, cabem posicionamentos que vão desde a permissão do aborto somente para salvar a vida da gestante, até sua permissão moral em outras circunstâncias.

Amparados por argumentos religiosos travestidos de jurídicos e tendentes a desconsiderar os direitos fundamentais das mulheres, tramita atualmente no Brasil, no Congresso Nacional, um Projeto de Lei que dispõe sobre a proteção do nascituro, conferindolhe a condição peculiar de "pessoa em desenvolvimento", (art. 6) (BRASIL, 2014). O artigo $2^{\circ}$ do referido Projeto conceitua o nascituro como "o ser humano concebido, mas ainda não nascido", chegando inclusive a compreender a fertilização in vitro, antes mesmo de o embrião estar no útero, de acordo com o parágrafo único do artigo.

A concepção passa a ser o marco inicial da proteção jurídica, sendo reconhecida a "dignidade e natureza humanas do nascituro" (art. 30) e vedadas "qualquer forma de negligência, discriminação, exploração, violência, crueldade e opressão, sendo punido na forma da lei, qualquer atentado, por ação ou omissão, aos seus direitos" (art. $5^{\circ}$ ). Conferindo ao feto não nascido os direitos fundamentais das pessoas, veda-se, tanto ao Estado quanto aos particulares, "discriminar o nascituro, privando-o de qualquer direito, em razão do sexo, da idade, da etnia, da origem, de deficiência física ou mental" (art. $9^{\circ}$ ).

Com o objetivo de garantir a proteção à vida do feto, em termos absolutos, o Projeto tenta retroceder inclusive na legislação penal, que estabelece os casos de aborto legal (risco de vida da gestante e gravidez resultante de estupro), e no entendimento do Supremo Tribunal Federal, que permite a interrupção da gravidez nos casos de anencefalia, ignorando absolutamente a gestante ao determinar atendimento pré-natal e psicológico para que a mulher vítima de estupro dê continuidade à gestação, prevendo ainda que a criança seja encaminhada posteriormente para adoção ou que a mulher receba alimentos por parte do agressor-genitor para a manutenção da criança, após seu nascimento.

Além de refletir o discurso masculinista antiabortista, o Projeto de Lei tenta conceder ao feto o estatuto de pessoa, em desenvolvimento. Assim, volta-se ao problema da doutrina 
jurídica que não estabelece qual seria esse conceito, muitas vezes confundindo-o meramente com a concepção de ser humano. Logo, se não há uma diferença conceitual, não há justificativa para priorizar o direito do feto em detrimento do direito de escolha e da autonomia da mulher.

$\mathrm{Na}$ filosofia, a definição de pessoa é justamente um dos principais problemas da metafísica, já que podem ser levadas em consideração diferentes características, tais quais a personalidade, a racionalidade, a linguagem, a autoconsciência, a agência, no intuito de diferenciar pessoas de outras formas de vida (BLACKBURN, 1996, p. 283).

Nesse sentido, Adams explica que o conceito de personalidade não tem valor neutro, sendo que ele nem sempre abrangeu todos os seres humanos e é definido pela cultura na qual as pessoas vivem. Quando se trata de atribuir personalidade ao feto, Adams (1998, p. 61) entende que seu corolário é a maternidade forçada. Essa mesma crítica é feita por Tiburi (2014, p. 171):

\begin{abstract}
A maternidade é, em nossa cultura, um código moral ao qual aquele que nasce com um corpo de mulher deve submeter-se. [...] A escolha livre das mulheres precisa ser defendida contra a menorização das mulheres pelo discurso masculinista que as submete à maternidade compulsória. Se a mulher deve se submeter à maternidade, ou seja, ao embrião, por fim, ela deve submeter-se ao que Elisabeth Badinter (2010) chamou de "sistema maternalista" cujo cerne é a tirania do bebê. A insubmissão do embrião à falta de desejo de maternidade define a soberania do embrião contra a escravidão da mulher. No discurso masculinista, o embrião está no cerne da gravidez, e não a grávida, assim como o bebê está no cerne da maternidade, e não a mãe. $\mathrm{O}$ feminismo é a crítica dessa postura.
\end{abstract}

O posicionamento antiaborto equipara a personalidade do feto à da gestante, mas Adams (1998, p. 61) afirma que o próprio fato de $92 \%$ a $96 \%$ dos casos de aborto legal realizados nos Estados Unidos serem feitos no primeiro trimestre da gestação, sendo mais da metade deles nas primeiras 8 semanas, demonstra que existem diferentes padrões para considerar a personalidade. Em muitos Estados nos quais o aborto é legalizado, é justamente esse o marco temporal (primeiro trimestre). Aliás, essa concepção também vai ao encontro do posicionamento de Dworkin, ao afirmar que o debate sobre o aborto esta pautado na questão de interesses.

Os posicionamentos divergentes decorrem, portanto, de padrões diferentes para definir a existência da personalidade. O critério para essa definição pode ser tanto o princípio da potencialidade quanto a atividade encefalográfica, a qual pode ser usada para definir tanto o início quanto o fim da personalidade. De acordo com esse critério, a personalidade pode ser reconhecida somente após o bebê ter alguns meses de vida, enquanto no outro extremo pode- 
se atribuir personalidade ao zigoto (ADAMS, 1998, p. 61).

\section{Considerações finais}

Uma breve análise dos aspectos históricos e dos debates jurídicos travados recentemente em torno da "questão do aborto" sinalizam claramente que não se trata de uma discussão meramente jurídica. Pelo contrário, os argumentos são permeados por uma perspectiva religiosa e fortemente imbricada em determinados estereótipos de gênero.

A ideia de que as mulheres estão "naturalmente" destinadas à maternidade e que socialmente devem arcar com estes custos obstrui uma discussão mais racional sobre a legalização do aborto, na medida em que a interrupção da gestação, não importa a condição concreta, implica em uma negação desse status de maternidade que seria o "destino natural" e o desejo mais profundo de toda mulher.

Sociedades fortemente marcadas por uma tradição católica são conformadas por um imaginário social em que a maternidade não se coloca como uma escolha, mas como uma obrigação que se impõe duplamente, como uma realização e como uma "punição" para as mulheres, que, caso tenham relações sexuais fora do escopo do casamento, devem arcar sozinhas com o ônus dessa escolha.

Verifica-se que os homens raramente são responsabilizados ou mesmo identificados nesse processo. O aborto é "só delas", no sentido de que a responsabilidade pela relação sexual desprotegida ou pela falha dos métodos contraceptivos seria inteiramente da mulher, ignorando-se o papel do homem nesse processo. Quando a mulher opta por manter a gestação, torna-se "mãe solteira" e a criança não tem o registro do pai. De acordo com o censo escolar de 2011, 5,5 milhões de crianças brasileiras não têm o registro do pai na certidão de nascimento.

Em última análise, coloca-se como uma forma extremada de controle sobre a sexualidade feminina, ao impor risco de morte àquelas que recusam a maternidade. Ao focar a argumentação pública sobre o direito absoluto à vida do feto, desconsidera-se o direito à vida das mulheres. E em um embate entre ambas as vidas, no discurso público, privilegia-se o feto em detrimento da mulher. Ignora-se as milhares de mulheres que ficam estéreis ou falecem em decorrência de procedimentos inseguros, sobretudo mulheres negras e de baixa-renda. Mulheres de classes sociais mais elevadas em geral não encontram obstáculos à realização do abortamento - viajando para países onde o procedimento é legal ou pagando altos valores por sua realização no Brasil - e, mesmo clandestinas, permanecem seguras. Considerando ser um 
problema que não atinge, portanto, diretamente as elites e que causa extremo mal-estar público, a discussão não avança no Congresso e permanece embaçada por obtusos argumentos relacionados à preservação da vida do feto a qualquer custo.

Há, portanto, uma dupla moralidade em vigor: uma que condena publicamente a realização do aborto e uma que a acolhe em "casos excepcionais" quando essa excepcionalidade se manifesta nas famílias das elites ou de pessoas que apresentam "boas justificativas" para a interrupção da gestação. O que se ignora, nesse processo, é que somente as próprias mulheres, sujeitos de suas histórias, podem efetivamente avaliar as condições de levarem a termo uma gestação. E esse julgamento, pessoal e intransferível, deve ser pautado pelos valores e crenças individuais, cabendo ao Estado o oferecimento de suporte médico e psicológico à decisão da mulher.

Simultaneamente, embora diversas religiões condenem ostensivamente a prática do aborto, essa condenação deve ter lugar no âmbito de cada comunidade religiosa e não no espaço público da atuação estatal, forçosamente laico por mandamento constitucional. É por isso que a argumentação religiosa que embasa a defesa da vida do feto a todo custo faz sentido no âmbito privado da vivência de cada crença, mas não pode ser imposta publicamente como regra moral à toda a população, ainda que em um país de maioria católica. Isso significaria infringir o direito à liberdade religiosa daqueles que professam outras religiões ou mesmo nenhuma religião, impondo uma única perspectiva à toda à sociedade e violando simultaneamente os direitos de laicidade na prestação de serviços públicos de saúde e de autonomia privada e liberdade religiosa de cada mulher. O campo jurídico - que também é da esfera pública -, também não pode utilizar o entendimento religioso sob pena de ferir a laicidade do Estado.

Se a atribuição de personalidade não é neutra e pode variar culturalmente, então ela não pode ser o critério moral para definir uma questão como a legalização ou não do aborto, no âmbito do Estado, seja em termos de legislação ou políticas públicas. A criminalização do aborto é contrária ao reconhecimento da mulher como sujeito dotado de direitos e constituição como indivíduo com interesses. A única individualidade alegada no discurso antiaborto é a do feto, separado da mulher como indivíduo e como se ele existisse em um vácuo moral. A mulher se torna um referente ausente (ADAMS, 1998, p. 58).

Vislumbra-se, portanto, que a doutrina jurídica é frágil ao estabelecer conceitos que visam fundamentar os direitos do feto, equiparando-o a pessoa humana. Assim, predomina um discurso masculinista antiabortista, segundo o qual a mulher é destituída de interesses e 
direitos, tornando-se mero meio para o desenvolvimento do feto. A teoria feminista contribui para a desconstrução desse posicionamento misógino e que mata milhares de mulheres na ilegalidade. 


\section{Notas:}

1 Para um estudo mais detalhado sobre a respostas dos tribunais brasileiros anteriormente ao julgamento da ADPF 54, consultar: GONÇALVES, Tamara Amoroso (coord.); LAPA, Thaís de Souza. Aborto e religião nos tribunais brasileiros. São Paulo: Instituto para a Promoção da Equidade, 2008. Disponível em: $<$ http://www.ccr.org.br/livros-revistas-detalhe.asp?cod=32>

2 Para uma análise profunda da forma como argumentos religiosos se apresentam como se jurídicos e imparciais fossem, consultar: GONÇALVES, Tamara Amoroso (coord.); LAPA, Thaís de Souza. Aborto e religião nos tribunais brasileiros. São Paulo: Instituto para a Promoção da Equidade, 2008. Disponível em: $<$ http://www.ccr.org.br/livros-revistas-detalhe.asp?cod=32> 


\section{Referências bibliográficas:}

ADAMS, Carol J. Neither Man nor Beast: Feminism and the Defense of Animals. New York: Continuum, 1994.

AVANCINI, Alex. Em decisão histórica França altera Código Civil e reconhece animais como seres sencientes. Agência de Notícias de Direitos Animais. 3 fev. 2015. Disponível em: $<$ http://www.anda.jor.br/03/02/2015/decisao-historica-franca-altera-codigo-civil-reconheceanimais-seres-sencientes> Acesso em: 15 fev. 2015.

BOBBIO, Norberto. A era dos direitos. Rio de Janeiro: Elsevier, 2004.

BRASIL. Lei $n^{o}$ 10.406, de 10 de janeiro de 2002. Institui o Código Civil. Disponível em: $<$ http://www.planalto.gov.br/ccivil_03/leis/2002/110406.htm> Acesso em: 16 fev. 2015.

BRASIL. Projeto de Lei $n^{o} 8116 / 2014$. Dispõe sobre a proteção ao nascituro. Disponível em: $<$ http://www.camara.gov.br/proposicoesWeb/prop_mostrarintegra?codteor $=1287642 \&$ filenam $\mathrm{e}=\mathrm{PL}+8116 / 2014>$ Acesso em: 15 fev. 2015.

CEDAW. General Recommendation No. 19 (llth session, 1992). Disponível em: $<$ http://www.un.org/womenwatch/daw/cedaw/recommendations/recomm.htm> Acesso em: 26 fev. 2015.

COMISSÃO INTERAMERICANA DE DIREITOS HUMANOS. Informe sobre la condición de la mujer en las américas. Relatoría Sobre los Derechos de la Mujer (OEA). Disponível em: $<$ http://www.cidh.oas.org/women/Mujeres98/Mujeres98.htm $>$ Acesso em: 11 nov. 2010.

CONSÓRCIO NACIONAL DE REDES E ORGANIZAÇÕES DO PROJETO DE MONITORAMENTO DA CEDAW. Caderno III: As recomendações como instrumento de trabalho na CEDAW. Coletivo Feminino Plural: Porto Alegre, 2015.

DINIZ, Maria Helena. O estado atual do biodireito. 3 ed. São Paulo: Saraiva, 2006.

DREZETT, Jefferson; PEDROSO, Daniela. Aborto e violência sexual. Ciência e Cultura, v. 64, n. 2, p. 35-38, abr./jun. 2012. Disponível em: $<$ http:/cienciaecultura.bvs.br/scielo.php?pid=S0009-

67252012000200015\&script=sci arttext $>$ Acesso em: 11 mar. 2015.

DWORKIN, Ronald. Domínio da vida: Aborto, eutanásia e liberdades individuais. 2 ed. São Paulo: Martins Fontes, 2009.

GONÇALVES, Tamara Amoroso (coord.); LAPA, Thaís de Souza. Aborto e religião nos tribunais brasileiros. São Paulo: Instituto para a Promoção da Equidade, 2008.

HTUN, Mala. Sex and the State: Abortion, Divorce and the Family Under Latin American Dictatorships and Democracies. Nova York: Cambridge University Press, 2003.

NADER, Paulo. Introdução ao Estudo do Direito. 34 ed. Rio de Janeiro: Forense, 2012.

ethic@- Florianópolis, Santa Catarina, Brasil, v.14, n.2, p.300 - 319, Dez. 2015. 
PERSON. In: BLACKBURN, Simon. The Oxford Dictionary of Philosophy. New York: Oxford University Press, 1996.

PIOVESAN, Flávia. Código de direito internacional dos direitos humanos anotado. São Paulo: DPJ Editora, 2008.

REALE, Miguel. Lições preliminares de direito. 27 ed. São Paulo: Saraiva, 2002.

TIBURI, Márcia. Aborto como metáfora. In: BORGES, Maria de Lourdes; TIBURI, Márcia (Org.). Filosofia: machismos e feminismos. Florianópolis: Ed. da UFSC, 2014, p. 163-176. 